
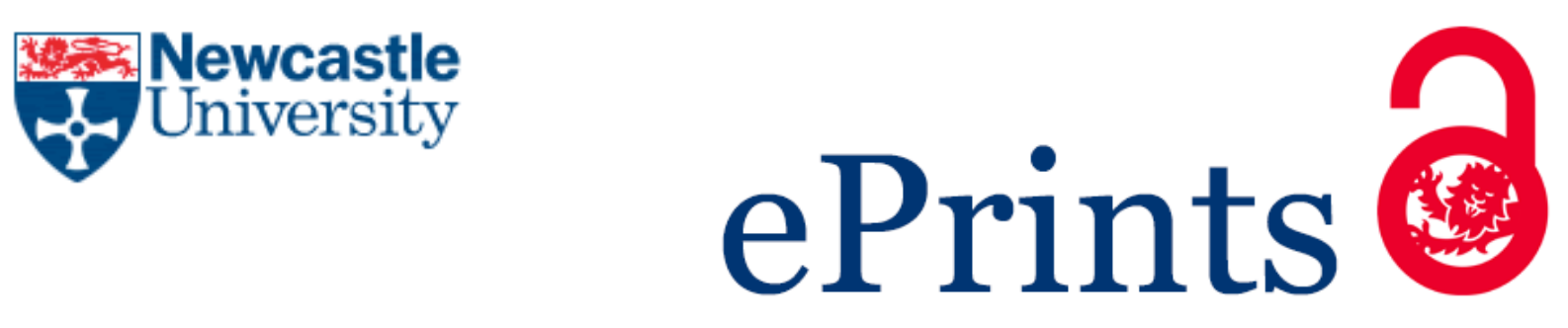

Pain R, Finn M, Bouveng R, Ngobe G.

Productive tensions: engaging geography students in participatory action research with communities. Journal of Geography in Higher Education 2013, 37(1), 28-43.

\title{
Copyright:
}

This is an Accepted Manuscript of an article published by Taylor \& Francis in Journal of Geography in Higher Education on 19/07/2012, available online: https://doi.org/10.1080/03098265.2012.696594

Date deposited:

$19 / 12 / 2017$ 


\section{Productive tensions: engaging Geography students in participatory action research with communities}

\section{Introduction}

This paper offers reflection on and analysis of a third year undergraduate Geography module which aimed to combine teaching and learning with University-community research partnerships, by involving students in conducting research with and for community organisations. The module focuses on the theories, practices, politics and geographies of participatory action research (PAR), a research approach that forms the mainstay of the students' project work. Participatory approaches to human geography involve undertaking research, teaching and other activities such as community engagement collaboratively (mrs kinpaisby 2008). Participatory research is increasingly mentioned in textbooks on research methodology in human geography (see Brietbart 2003; Kesby et al. 2005; Kindon et al. 2007), and some human geography undergraduate curricula teach or use participatory methods such as diagramming (see Hopkins 2006; Kesby 2000). However, participatory research involves far more than participatory methods; using these methods alone does not constitute participatory research, and participatory research may use any methods, including more traditional techniques (Kesby et al. 2005). Teaching PAR, then, is not primarily about teaching a set of methods (Kindon and Elwood 2009). Vitally, it involves engaging students in an epistemology and ontology of knowledge which differs from those which are predominant across Geography curricula; it involves challenging mainstream hierarchical modes of knowledge production that are taught and practiced across the discipline.

Participatory action research (PAR) is a specific participatory approach, offering 'a collaborative process of research, education and action explicitly oriented towards social transformation' (Kindon et al. 2007, 9), often used to challenge the socially unjust situations in which people find themselves (Savin-Baden and Wimpenny 2007). It frequently involves collaborations between different partners who have specific sets of skills and knowledge. Where academic researchers are involved, they may have greater or lesser roles in framing and leading the research. Classic examples in geography include long term, collaborative and iterative research involving geographers working in partnership with groups such as Cahill's work with undocumented students in the USA (Cahill et al. 2008); Kindon's participatory video project with the Ngāti Hauiti tribe in New Zealand (Kindon 2003; HumeCook et al. 2007); Gibson-Graham's (2006) involvement in action research on local community development in North America; and Cieri's work on a range of community arts projects also in the US (see Cieri and McCauley 2007).

The profile of PAR in geography has been boosted by the recent resurgence of radical action-oriented approaches in the discipline, and the growth in engagements and alliances between geographers and non-academic organisations and activists (Hubbard and Kitchin 1999; Kindon et al. 2007; Pain 2003). In Fine's words: 
PAR is, at once, social movement, social science and a radical challenge to the traditions of science... [it] deliberately invert[s] who constructs research questions, designs, methods, interpretations and products; who engages in surveillance. Researchers from the bottom of social hierarchies, the traditional objects of research, reposition as the subjects and architects of critical inquiry, contesting hierarchy and the distribution of resources, opportunities and the right to produce knowledge.

(Fine et al. 2007, xxx)

These goals are lofty ones when applied to the realities of a third year undergraduate Geography module, where students must learn how to conduct PAR, get to grips with its political and conceptual underpinnings, and complete research projects within a 20-week teaching period. For all of those taking the module, this was their first knowledge and experience of PAR. Most had conducted fieldwork independently for their dissertations (a major independent research project, commonly undertaken in the second and third years of English undergraduate programmes), but the projects they were now faced with had very different goals. The module did not aim to set up participation as an unachievable 'gold standard' (Kesby et al. 2005) that students must attain to get a pass mark. Instead, it presented a set of philosophies, principles and practices to critically engage with and work towards; the projects were framed as 'real world' attempts that would almost inevitably fall short of the ambitious goals of PAR, but that nonetheless might produce research that was useful for community partners and a rich learning experience for students.

The projects, or rather agreements that there would be projects of some sort, were put in place by Rachel before the module began. She is the professor who runs the module, and a member and Co-Director of Durham University's Centre for Social Justice and Community Action (see www.dur.ac.uk/beacon/socialjustice). The Centre was founded in 2009 to support PAR research projects between the University and the community sector, and to connect local, national and international networks of community, voluntary and public sector organisations to teaching, postgraduate supervision, training, seminars and conferences. Durham is an elite UK University with little history of collaborative research with its immediate communities, despite being located in one of the most socially and economically deprived counties in the UK (Russell et al. 2011). A few years ago, consultations were undertaken prior to the university's formal public engagement efforts beginning, and these showed that local communities did not view the University as serving their needs well. The idea that the resources and skills of University staff and students might be harnessed to directly benefit local communities was a popular one. The philosophy of the Centre for Social Justice and Community Action (and one which underpins this taught module), is the co-production of knowledge, rather than one-way knowledge transfer. Each project developed on the module comprises a small 'knowledge community', where a range of participants, including students, bring their skills and expertise to collaborative research. 
Outside the UK context, others have led the way in combining PAR with teaching in Geography. Kindon and Elwood (2009) offer an excellent review of the various traditions in different national and institutional contexts that facilitate such engagements. As they illustrate, drawing PAR into undergraduate teaching and supervision 'destabilize[s] traditional hierarchies of researcher/researched and teacher/learner' (Kindon and Elwood 2009, 20; see also Cope 2009; Elwood 2007, 2009; Moss 2009; Mountz et al. 2008). In recent years there have also been similar efforts in other disciplines (Bidart-Novaes et al. 2008; Hofman and Rosing 2007; McNicoll 1999). It is an approach that can be challenging for all involved but, these authors agree, a valuable one that offers the potential for more socially just modes and outcomes of teaching and research.

In this paper, we aim to contribute to this wider understanding of using PAR to combine teaching and learning, research and community engagement in Geography. To date this literature has not included perspectives on the process held by students and community partners, yet these are vital to the success of such initiatives, given the centrality of collaboration to PAR. While undergraduate students are often presented as the primary reason for making the choices we do around teaching, they very rarely feature as authors in this journal. Our analysis does not pretend to be representative of the wider field or possibilities, coming from a relatively small module in one University, and written by one member of staff, two community partners and one student (although we also draw on wider evaluations from students and community partner organisations). What we hope to raise are a series of issues to debate, to inspire and perhaps to caution others.

The aim of the paper is to evaluate the module and its contributions to student learning and community organisations. It does this through reflective analysis from each of the coauthors, drawing in places on evaluations from the wider group of students and community partners. We then draw together some common themes: the productive tensions that run through this kind of teaching through community engagement. The paper is not an evaluation of the particular PAR projects that students undertook with community organisations. Nonetheless, details of two examples of projects are given in passing within our reflections on the module (and see Box 1 for a précis of each).

Four of us have co-authored this paper: Matt (one of the students who took the module), Gloria and Rebecca (project coordinator and secretary of one of collaborating community organisations), and Rachel (the academic who designed and taught the module). In keeping with the goals of participatory action research, we have deliberately constructed the paper as a polyvocal account (see Cahill and Torre 2007). PAR projects are collaborative, but the different partners involved may have diverse perspectives and priorities (see Pratt 2007). In this case, it emerges from our analysis that the teacher, students and community partners have some differences in expectations and priorities. When analysing the contributions, potential and problems of this module, we feel it is important not to erase these differences in an output that largely reflects one view. Indeed, tensions and potential conflicts in 
achieving the diverse aims of the module can be viewed as productive to teaching and learning, to community partners, and to the research produced.

In what follows, we first describe the aims and operation of the module. Gloria and Rebecca, as collaborating community partners, then reflect on and evaluate the module and some of its outcomes from their perspective. Matt considers the overall evaluation from students, and draws out some themes within these, developing the notion of tensions. Next, Rachel reflects on the goals and outcomes of the module from her perspective as the teacher. Finally, in the conclusion, we reflect further on the key themes and tensions that arose, which we hope will provide some guidance for others who run or intend to develop this kind of module.

\section{The module: "People, Participation and Place" (Rachel Pain)}

At the time of writing, "People, Participation and Place" has run for two years. It is a yearlong 20-credit module available to BA, BSC and Joint Honours Geography undergraduate students at Durham University in the UK. The aims of the module are (i) to support students in developing critical understanding of the theories, practices and politics of participatory development and research in a range of global contexts; (ii) to develop students' skills in developing, undertaking and reporting on a participatory project in collaboration with a local community organisation; and (iii) to encourage reflection on the intersections of theory and practice in participation, and the importance of geographical concepts and methods to this relationship.

The module is taught through a set of core lectures on the history, theories, politics, practices, methods and ethics of participatory development and research in the first term. In the second term, students work collaboratively with local community organisations in north east England on participatory research projects. Working in groups of four to five students, they have a series of meetings with community partners to discuss the shape of each project, after which they write a project proposal which is formatively assessed and then shared with community partners. They complete ethics and risk assessment documentation, and each project has to be cleared by the appropriate local committees before they proceed ${ }^{1}$. Students then conduct fieldwork over two months (Box 1 outlines the two examples of projects which we reflect on later in the paper). Weekly workshops are held with the whole class to discuss progress, troubleshoot problems, and relate what is happening in the field to set readings which are academic papers on aspects of PAR. Group reports to the organisation make up the first piece of summative assessment, and are accompanied by a more reflexive individual piece of writing in which students draw on concepts in current literature to appraise their practice and experiences. Finally, a seen exam paper assesses students' integration of practical and conceptual issues from their learning across the module. The philosophy underpinning the teaching and learning on the 
module is Freire's (1972) notion of praxis, which is also a keystone of PAR (see Kindon et al. 2007): at every stage of the module, students are asked to work cyclically and reflexively, between theoretical and practical issues and between the spaces of the classroom and the field (see also Elwood 2009).

\section{Box 1: Two examples of student PAR projects}

Project A: Experiences of discrimination among asylum seekers and refugees

Students worked with ASC'EM and refugees and asylum seekers, together developing the research question of understanding and suggesting solutions to experiences of discrimination in County Durham and Teesside. They held a number of discussion groups and informal conversations to collect preliminary data and provide qualitative description. The issues raised were then the subject of a questionnaire that was more widely distributed, analysed and interpreted with the participants.

Project B: The assets and needs of small community organisations

Given contacts initially through Durham Council for Voluntary Service, students worked with a number of community groups in a local ex-mining village, to investigate with them their existing assets, resources, needs and requirements. A number of discussion groups were conducted using participatory methods, and participants were involved in analysing and interpreting the data. The aim was to make recommendations that would enable the County Council's Area Action Partnership to support these groups more effectively.

We now move on to our individual evaluations, as partners involved in the projects.

\section{Reflections from community partners (Gloria Ngobe and Rebecca Bouveng)}

We are project coordinator and secretary respectively of ASC'EM, a community organisation that supports refugees and asylum seekers in north east England. The organisation has hosted three student projects in the two years that the module has run, involving students and asylum seekers working together to develop research questions, explore using various methods, analyse and report on a research topic of common interest. We offer comments here in relation to the first and second year of our involvement, offering more detail about one of the student projects (Project A in Box 1), and appraising the benefits and issues with the module.

\section{The benefits of the module for our organisation}

We found it very rewarding to deal with students. It was clear that they had no experience of the lives of asylum seekers/refugees, but they were willing to learn and understand more 
about our organisation and what we do. They were very good listeners, and I am sure as individuals they now have a different view of asylum seekers/refugees. They also came across as very sympathetic about some of the stories they heard; they seemed shocked about some of the asylum seekers' experiences in this country. They were a great joy to work with and never complained about anything. They were very respectful, unlike perceptions of the 'typical student', and they were keen to know more about different cultures. The report they produced focused on the issues faced by asylum seekers and how this can be used to work towards community cohesion and reduce exclusion. It is useful for those who really want to know the issues faced by asylum seekers, as the media has already inaccurately portrayed a certain image of what asylum seekers are and what they do. The report had a clear and appropriate scope, and its practical, straightforward approach has been very helpful (see Box 2 for evaluations of different projects from other community partners).

I (Rebecca) was shocked at the extent of the everyday racism the report indicated. I knew of specific issues and incidents our service users face but I hadn't realised the extent of racism, even amongst bus drivers. I (Gloria) was not surprised by the findings, because I know that the racist incidents reported do happen, and can be worse, so to me they are only the tip of the iceberg. I am sure the students would have been told a lot more, but the clients did not really develop full trust until near the end of research; only then did they started to talk about sensitive and personal experiences.

We appreciated the time the students took to talk to clients in the research, as we do not have the time or capacity to do this kind of data collection. It also creates an awareness of the willingness among our client group to integrate with the wider community, rather than be excluded. The project has been beneficial for participating service users who have appreciated being listened to, and taking active part in something like this rather than just being passive 'receivers' of services.

The collaboration has been very valuable, both in terms of the project itself which service users saw as beneficial (being listened to, and taken seriously), and having a professional academic report which benefits our organisation. The project has improved our credibility as an organisation supporting ethnic minorities and challenging racism and prejudice. We see it as an opportunity to educate the public about asylum/refugees, and we will continue to open our doors to those who genuinely want to know more about what we do and the clients we work with. The project has also been a trial that has opened our minds about what more extensive participatory research can do to change communities and the way we do our work.

In terms of follow-up action, we have passed the report onto Stockton PCT and Stockton Police, and discussed it in the Stockton Police Independent Advisory Group. We will continue to use it as evidence to funders and others for the need of our work in supporting ethnic minorities, as well as working at different levels to challenge racism, prejudice and 
discrimination. The students themselves offered to write a letter and enclose the report to the Arriva bus company, as the racism of bus drivers really stood out.

\section{Suggestions for improvement}

We made some critical suggestions for improvements between Years 1 and 2 of the module running. We felt that the stage at which we familiarise and introduce students is essential, and more time is needed for this. For example, it would be best if students visited the church attached to our centre before they actually started the research, have a cup of tea and a chat to some members, so that their faces can become familiar. This would have generated more trust and willingness to share on behalf of the service users. (We know that third year students are pretty busy though!)

\section{Evaluation of the second year}

In the second year that the module ran, we felt that the student projects were markedly different from the first. The main reasons for this were the individual engagement of this year's students, and the closure of one of our drop-in centres due to funding cuts, which meant that students had to be much more flexible in accessing our service users and volunteers. It was good to see that most of our suggestions from the previous year's evaluation were taken on board, especially about how we could improve the relationship between clients and students. We encouraged them to just come along to meetings in the beginning, without openly doing research, to get to know people and build up trust. Much to their credit, many of this year's students did so willingly, participating in different activities which were not centred on the research, trying to get to know people personally. Each time the students came along, we sought to present the research project to the participants, encouraging them to participate and to share their experiences, and we explained its purpose. For some of the service users, perhaps cynical from past experiences in this country, the issue of trust persisted - rumours spread at one point that the government was giving ASC'EM money in exchange for information, extracted by the students, about specific asylum seekers. But despite these issues, a number of the students managed to build good relationships with our service users, meeting up with them outside of ASC'EM meetings for individual interviews and small group sessions.

What the students learnt in these meetings seemed to affect them quite a lot. In one meeting half-way through the project, one of the students told the audience, mostly African refugees or asylum seekers, how he had been moved by the stories he had heard over the past weeks. He described his own sheltered British middle class upbringing and confessed that he used to be quite prejudiced against asylum seekers. He would never have believed, he said, the things that were going on in his own country, and thanked people for sharing their stories. Then he finished by saying he would like to apologise on behalf of the British people for their prejudice and for the injustices committed against asylum seekers here. Everyone had tears in their eyes. This became an important moment in the project, and for 
us, it is good to see that even if we might not be able to change the way society views asylum seekers, one person has come to see things differently.

We understand that the value of participatory research at this level lies not only in the end product - in this case the report - as in the actual participation. As someone (Rebecca) who has been a Durham undergraduate and later postgraduate, a community volunteer working with asylum seekers, an agency care worker working with 'locals' across the county, and on top of it all a foreigner, I believe this module and approach to research is particularly valuable in Durham, as the gulf between the different social worlds is extreme here. It invites participants to visit and understand a world different to their own, hopefully helping in a small way to bridge some of the gaps.

\section{Box 2: Examples from community partner evaluations of projects}

The following comments come from evaluations conducted with the wider group of community organisations involved in PAR projects the first year of the module. Their evaluations of the students' work were overwhelmingly positive.

"They took a very professional approach and were able to adapt their methodology to fit in with [our] needs and suggestions"

"Professional, always on time, gave us detailed plans of what their objectives were during each session"

"We found the use of video-ethnography very interesting...a new approach and one we would like to repeat in the future"

"The report was clear, concise and well written"

"The findings will be taken into consideration when planning new galleries"

\section{Reflections from a student (Matt Finn)}

I was a final year undergraduate who took this module during the first year that it ran. I worked in a student group on Project B in Box 1 . In this section, I interweave my own personal reflections on the module with feedback from fellow students' written evaluations given the end of the first year the module ran. In what follows, I have chosen not to adopt a form that might try to secure the status of my writing as appropriately scholarly ('for a student'). Instead I write to present something of the everyday reflection and analysis we engaged in as students in the process of our projects and study on this module. Though students engaged in different projects, our feedback was consistently positive in tone. This was a module that we as students found enjoyable, and for one it was "the best module I have done throughout my degree". It was also a challenging module, and some of the 
positive feedback is not in spite of but because of this. I would like to draw attention to some of the contradictions we experienced on this module, and will highlight three of these. These pairs of contradictions are not mutually exclusive, and our experiences as students shifted back and forward between them over time and in different spaces.

\section{Students as CV-builders / citizens}

Some of our student feedback focused on the value of the course:

"Did something useful with our learning"

"Being able to use what you've actually learnt in the real world!"

"Something for the CV"

"Having the opportunity to write a report and work with [an] organisation"

"Worthwhile research for others as well as for us"

It is not uncommon to hear from other students that one should do this community work or that college welfare role because 'it'll look good on your CV'. As third year students, many of us were thinking about what would come next, and about the increased difficulty in finding paid employment. Towards the end of the degree programme, many fellow students had job interviews where they were asked for examples of their experience of group work, collaborative report writing, of how they respond when things go wrong, and so on. Taking this module furnished them with neat bite-size accounts that they could serve up to interviewers.

By contrast, the ideals which informed the course, around notions of praxis, emancipatory and activist strategies, for example, seem to suggest that the subject position the student would inhabit would be that of citizen or social actor. Indeed, the framing of the project I took part in (see Project B in Box 1) very much fitted with these concerns. The normative expectation we worked with was for projects that were not extractive, and that benefits should not migrate away with the end of the student researchers' involvement. Student feedback was in fact positive about the value of the projects for all of the participants. Yet, at the same time there was an awareness that our experiences as students could be so easily repackaged and mobilised to serve our CV building or career aims, offering a competitive advantage over other job applicants. Could the same be said for the nonstudent participants? For me this raises questions as to the ability of PAR principles and practice in the context of university to challenge the issue of who benefits from research and to what ends. Very much connected with this was our experience of learning.

\section{Learning as consumers / participants}

Some of our feedback reflected on the positive experience of learning in the course:

"Geog[raphy] can be different, not rigid and pre-defined"

"Helped put theory in context" 


\section{"Group work and learning through practice" \\ "You can do research without reading" \\ "Thinking outside an academic context" \\ "More autonomy in the research process"}

Whilst a gross generalisation, I think many students (including myself) work with an expectation that lecturers are there to serve up a knowledge product that we as students consume. Many of us expect to get a degree and a 'good one' because we think we paid for it (though at the same time we recognise we pay not for a degree but tuition, through 'tuition fees'). This module required us to consciously adopt a different attitude and posture towards learning. While group work is a fairly common feature of our university life, nowhere else on our degree programme did the group itself include non-students. This demands something of us - the information transfer model of other courses really requires relatively little of us as people - whereas here we are plunged into the complicated reality that what we do, decide, omit or suggest can have immediate and obvious consequences for people other than ourselves. Many students appreciate the freedom this process offers. Indeed, I found that the ethical and political questions about power, representation and knowledge taught as part of the academic content of the module really came alive.

For example, where one participant was quite dominant, often speaking on behalf of others or the group, how do you respect that person's contribution whilst making space for other stories and views that may disagree? We found that simple strategies like breaking down into smaller groups and feeding back was helpful. We also found that as students we needed to work carefully together, often using non-verbal signals so that we could guide the process through. This meant negotiating carefully with those who were sometimes two or three times our age, so as to limit the role of those that might dominate and hear from those who otherwise might not have spoken.

These issues necessitate engaging with those you meet as whole people, not just sources of data, and require much more whole-person engagement on the part of us as students, not just intellectually but socially and emotionally. Many of us found that thrilling but also challenging, as sometimes we didn't want to engage emotionally with something or say how it affected us personally - we would have preferred to remain detached and not have to own a position. Sometimes we wanted to do the work, be done with it and get our grades.

Rachel set the tone of a supportive environment where ethics of care applied just as much to one another as to community participants. I think this was vital as students may themselves be facing issues that mean that it is not possible for them to engage with other participants to the level the course requires and their fellow students expect. It seems important to me that students should be challenged and yet not feel compelled, by the group or grading structure, to participate to a level which would never be required of all community participants. The principle of ongoing, informed consent which allow and respect participants' choices about the level at which they wish to engage should at least be considered in relation to students as it is with community partners. This leads me to my last contradiction.

Results as 'Our degree' / 'Their lives' 
Some of our feedback related to our perceptions of the importance of the course:

"Provid[ing] a listening ear to people who don't usually get listened to"

"[I] know myself better"

"Research doesn't have to be extractive and just benefit the researcher"

Whilst during the project it is possible to think more democratically about all the partners as genuine participants, at certain points this mentality shifts. Mainly these shifts coincided with coming back into the lecture room. The 'us'/'them' dynamic re-emerged most strongly when it came to assessed work, where it feels like the whole experience is going to be reduced to a grade. The struggles of participants and shared hopes, the waiting week after week for certain partners to arrange an introduction for us and uncertainty about whether we would be able to do the planned project in time, the group discussions, the negotiation of differences and the friendships formed, the nervousness before the first meeting with community partners and the sadness and relief of the last. All these experiences reduced to one grade and it is a number that feels like it matters. Helpfully, Rachel sent us some feedback from community groups after the assessed elements of the course had been completed. This feedback helped to bring a fuller perspective to the question of what matters to whom.

For all the highs and lows we experienced, the lasting impression both for me and in the student feedback overall is a positive one. Whilst many of us didn't quite know what we were letting ourselves in for, everyone I have spoken to would willingly choose the course again. There is a hunger for something different, something that asks, indeed expects more of students, something which is well-connected with the local area and engages with difference. Without wanting to overstate the projects' successes or underplay their difficulties, the consistent response from students was that the course was different, engaging and a welcome addition to the undergraduate degree program.

\section{Reflections from a teacher (Rachel Pain)}

\section{Professional and personal motivations}

Several factors motivated me to set up the module. I had taught in universities for 15 years, but increasingly felt there was a disjuncture between much of my teaching and the way that I have tried to approach the research I am involved in (see Pain, 2003; Pain and Kindon, 2007; Askins and Pain, 2011). A key tension within the mainstream human geography undergraduate curriculum is that we may teach students about 'critical' or 'radical' ways of seeing the world, but very rarely engage them in anything resembling radical pedagogy or research. The University as producer of the knowledge that makes up degree programmes is not questioned. Even where teaching is research-led, the relationship between research and teaching is predominantly one-way (Healey, 2005) and, in many countries, the dichotomy between them is growing (LeHeron et al., 2006). These are tendencies that entrench elitist models of knowledge production - universities are presented as the sole site of knowledge, 
and students need not stray outside their boundaries to learn everything that they need to know (Pain 2009). I also wanted to think about how our students' knowledge and energy could be used for some benefit, while students might develop a set of skills and experiential knowledge which they do not gain from academic study alone. I was inspired by the teaching practices of colleagues in New Zealand, the USA and elsewhere (see Kindon and Elwood 2009), and led, as Sarah Elwood (2007, 2295) was, by the 'creativity and resourcefulness' that other academics have shown in achieving these goals (including Sarah herself). How can undergraduate teaching feed more directly - even at a small and local scale - into the socially just changes that many geographers would advocate (see Askins 2008; Howitt, 2001; Motta, forthcoming)? From the student comments Matt discusses above, this goal emerges as one of the aspects of the module that they most value.

For myself, I wanted to fold my teaching more closely into my research and work with community organisations (see mrs kinpaisby, 2008), rather than keep them as separate activities that are always competing for my time and attention. This is not to say that this model of teaching saves any time - I experienced all the logistical challenges and late nights that go into preparing a brand new module; and there are additional responsibilities such as of setting up projects and mediating between community partners and students, in one case finding a new project at the last minute when the one initially planned was too slow in coming through. But bringing these spheres of work into closer union - with their personal and political dimensions necessarily upfront - has a logic to it, and potentially offers for the teacher more of the 'whole-person engagement' that Matt describes above for students (see also mrs kinpaisby, 2008). This was a satisfying and engaging module to run and to teach, and it fed back into my other research activities. Because students were actively bringing issues back into the classroom each week - a whole range of intellectual and practical problems, questions and insights - my knowledge and thinking had to remain active, supple and dialogical too.

\section{Response to evaluations}

It was important, if nerve-racking, to evaluate the first year of the module, and to go beyond the standard University student feedback questionnaires in doing this. I asked students to answer an additional questionnaire which had open-ended questions that were specific to the learning outcomes of the module. Their answers were anonymous. I also asked the community partners who were involved in the first year to do the same. The comments from these two wider groups, that punctuate Gloria, Rebecca and Matt's reflections (above) are drawn from this more extensive evaluation process. The feedback fed into the design of the second year of the module. The feedback was generally extremely positive.

However, these evaluations and my co-authors' reflections (above) do contain surprises. It was eye-opening to hear from Matt not only the positive things that students got out of the module, but the contradictions they experienced which I hadn't anticipated. I knew the module would be different, challenging, and involve students in facing messiness and 
uncertainty head-on; but I was thinking primarily in terms of students' experience as knowledge producers rather than as consumers of education. Indeed, if anything, I was enthusiastic about providing a module that downplayed and perhaps even subverted the 'education as consumption' model. Especially given the context in which undergraduates now sit in the UK, with tuition fees rocketing from 2012, and a worsening graduate employment situation, these are tensions that clearly need to be acknowledged, addressed, and worked with rather than against. Yet finding fair ways to pursue social justice-oriented, integrative teaching and research, have become more rather than less urgent in a neoliberalising context. Similar arguments have been made about exposing students to radical geography within the classroom; but my experience is that the impact of learning through direct personal interaction outside the classroom has more profound effects.

Of importance, too, are Matt's comments about 'whole-student' involvement: the ethical issues surrounding how far students are expected to engage personally and emotionally with the projects and module. His point about applying the principle of informed consent to students, as well as other research participants, in terms of their level of engagement, is a vital one. Students going through difficult personal issues may need extra support or sometimes exemption from certain activities and demands.

The greatest change in my perception of the module and its potential outcomes comes from community partners' evaluations. I realised after reading these evaluations and talking to several of the partners after the module had ended, that the advantages they see are not just about receiving something concrete from students and the University. As Gloria and Rebecca make clear above, the benefit they see is just as much about giving students new appreciation and understandings of the situation of others. Several community partners commented that if some of those students go on to take this emotionally-grounded knowledge out with them to their relatively powerful positions in the wider world after they graduate, that may be one of the most significant ways in which the module can make a difference.

\section{Conclusion: working through productive tensions}

Overall, then, within its constraints and in a modest way, the module met the goals and principles of PAR. We suggested at the start of this paper that modules like ours involve[s] engaging students in an epistemology and ontology of knowledge which differs to those which are predominant across Geography curricula'. This comes across from student evaluations and the experiences of co-producing knowledge that the module offers all participants. Although we did not aim in this paper to evaluate the specific PAR projects we ran, each project has been academically rigorous and useful. Benefits also come to students, community partners and the teacher, we suggest, from the process of collaboration. 
We end the paper by identifying five key issues or tensions that cut across the evaluations and reflections on the module. These may provide some guidance for those considering developing modules animated by similar concerns.

The first is the value of engagement through the building of relationships between those involved. Modules such as this one demand the effective use of a wider range of 'soft' as well as 'hard' skills (Kindon and Elwood 2009) - whole-person engagement that is simultaneously intellectual, professional, social and emotional. In Matt's and Rachel's reflections, they highlight this as central to PAR and how they teach and learn it, and Gloria and Rebecca focus on the need for students and participants to get to know and trust each other as people for the research to be a success. Value is attached to these interactions as encounters which mitigate against the experiences voiced of students and asylum seekers as being socially isolated in different ways. The example of the student who was moved enough by what he had learnt to apologise to a meeting of asylum seekers shows something of the emotional engagements that this research can involve.

The second, intrinsically linked to the first, is the more pragmatic issue of time. It is recognised in different ways by all participants that the promise of deep personal engagement, relationships and deep experiences of learning seem to stand in conflict with demands on them from elsewhere. It seems important to acknowledge the costs (which are not necessary financial) of participation that imply the commitment of oneself to others. This is a key tension for academic staff teaching modules of this nature (see also Elwood 2007; Kindon and Elwood 2009; Mountz et al. 2008). In the UK, unlike in the United States, there is no formal service learning element in higher education (though that is not to say involvement in service learning comes at no cost to US geographers; see Mountz et al., 2008; Cope, 2009). In our institution in the UK, all of the time students spend on their PAR projects has to be accounted for in the same 'SLAT' hours (Student Learning Activity Time) that traditional modules were bound by. Yet what students learn is that to work well, PAR requires time to build relationships, develop research agendas and conduct fieldwork (mrs kinpaisby, 2008). On our projects, all partners had considerable constraints on their time and we had to work within these. The demands of the academic timetable and annual cycle do not necessarily fit with the demands of PAR (Kindon and Elwood 2009). Community partners, in particular, are now operating in a context of growing cuts to their grants, budgets and staff time. The UK voluntary sector has seen cuts of up to $70 \%$ in budgets during 2011 (The Guardian 2 Aug 2011), and it may be that this deters participation in student projects in the future. On the other hand, there is a greater argument for sharing resources between universities and local community organisations, and synergies between university teaching and community research may be more valuable than ever.

The third area of tension is between teaching and learning styles, particularly information transfer versus reflexive learning. Rachel mentioned above her desire for radical pedagogy and research to be reflected in undergraduate teaching, but in reality, these projects and her own teaching style could only be relatively radical (and only in comparison to other 
modules; they hardly come anywhere near Freire's (1972) model for radical education). On the one hand, the module aimed for a praxis-based model of teaching, teaching in ways that involved open discussion and engaged students in reflecting on their own lives and experiences, and making frequent use of hands-on diagramming techniques that encourage this style of learning (Hopkins 2006) as well as providing practice in some of the methods they might later use on their projects. Teaching and learning were also relational and reflexive, in that students brought issues and problems to class each week, and Rachel responded to these as best as she could. But on the other hand, she still felt under pressure to pass information on, and a lot of it, given the breadth of the curriculum that she had decided needed to be covered in the first term. Beyond teaching methods in class, then, the module as a whole was itself participatory only around the margins. At our University, students cannot be involved in developing course aims, deciding content, or setting assignments in a serious way. Nonetheless, positioning Rachel and the participants as the informers (of a body of theory or of experience) could have figured them as passive regurgitators of knowledge, and the students as passive recipients of their knowledge, and yet this would be to ignore the creative ways in which all participants engaged with, questioned, employed and reconfigured those knowledges in the spaces of encounter and in the final written reports. The nature of the pedagogic interaction nevertheless remains something that is experienced as a problematic.

A related issue is one of failure. Rachel's view is that attempts at PAR may often fall short of their desired goals, but may still produce valuable research, and always result in enriched learning for those involved. For her, it seemed that some of the most important learning for the whole class came from the moments when a student group dejectedly reported some 'failure' in collaborating with participants to the extent that they had planned, and from group discussions about how to respond, and indeed to what extent this 'failure' mattered or was a failure at all. We learnt as each project developed something that cannot be adequately demonstrated in textbooks - that PAR never follows idealised paths, is sometimes contradictory, always unpredictable and often surprising. The student projects that have been the least structured and directed by the organisations involved tended to result in the deepest levels of participation. As geographers, we saw context as crucial: particular combinations of geographical, social, organisational and personal factors shaped each project (see also Bidart-Novaes et al. 2008; Kindon and Elwood 2009; Maddison and Laing 2007), and students ably unpicked these in class and in their assessed work. At the same time, we had a considerable responsibility to ensure that these rich learning experiences did not occur at the expense of the projects or participants; we aimed for ethical, respectful, accountable and useful research, sometimes in tricky circumstances.

For students, however, the place of 'failure' is more problematic, given it is the one thing above all they are encouraged and motivated not to do in the rest of the curriculum. This was not mentioned in student evaluations, but Matt reports that it was a significant point of discussion during the module. Where there are expectations of high grades, a module which 
has failure as part of its pedagogy may prove challenging for students and appear hazardous for other participants. We should be clear here that projects that 'failed' in some ways (i.e. did not meet the mark as fully participatory pieces of research) did not receive lower grades. Most 'failed' in that respect, as we would expect. But expected outcomes are viewed as more precarious than on other modules where the curriculum and modes of assessment are more uniform and predictable. This was a source of student unease, and underlines the importance of an ethos of care between and among all participants, that still allows for outcomes that are not pre-defined.

To conclude, in agreement with Kindon and Elwood $(2009,23)$, combining PAR with teaching and community engagement is not a "panacea to the growing demands placed on academics to excel equally in research, teaching and community service and to do so with ever-diminishing resources'. This form of teaching does not necessarily fit easily with institutional structures and arrangements (Elwood 2007), or initial student expectations. However, it is one that is well worth pursuing; the evaluations reported here demonstrate the positive difference that it made on our module to students, staff and community partners. As an approach to higher education, it is motivated by a desire to forefront social justice outcomes in difficult political and economic times. As we have sought to show, there are inevitably tensions around achieving the diverse aims of such modules. Teachers, students and community partners go in and come out of these encounters with different priorities and perspectives. But if these differences are discussed and tackled head on rather than glossed over, we would suggest, this can make for very productive and rewarding experiences for all of those involved.

\section{$\underline{\text { Notes }}$}

${ }^{1}$ A number of authors identify ethical clearance as a potential issue with such student research projects. However we had no difficulty gaining clearance for our projects or the open-ended nature of PAR. Where projects changed significantly after the proposal stage, we applied for updated clearance.

\section{Acknowledgements}

We would like to thank all of the students and community partners who contributed to this module and its evaluation in 2009-10 and 2010-11, and to the three anonymous referees. Rachel is very grateful to Sara Kindon, Sarah Elwood and Andrew Russell for providing advice and examples when she first set up the module. 


\section{References}

Askins, K. (2008) In and beyond the classroom: research ethics and participatory pedagogies. Area 40, 500-509

Askins, K. and Pain, R. (2011) Contact zones: participation, materiality and the messiness of interaction. Environment and Planning D: Society and Space 29, 803-821

Bidart-Novaes, M., Gil, A. C. and Brunstein, J. (2008) Management teaching and research: Participatory Action Research making possible new forms of dialogue between community and universities. Journal of Academy of Business and Economics 8, 2, 167

Breitbart, M. (2003) Participatory research methods. In Clifford, N. And Valentine, G. (Eds) Key Methods in Geography 161-78

Cahill, C., M. Bradley, et al.. (2008). "Represent": Reframing risk through participatory video research. Video Vision: Changing the culture of social science research. M. Downing and L. Tenney. Cambridge Scholars Publishing.

Cahill, C. and Torre, M. E. (2007) Beyond the journal article: Representation, audience, and the presentation of participatory research. In Kindon, S., Pain, R. and Kesby, M., editors, Connecting people, participation and place: participatory action research approaches and methods, London: Routledge, 196-205.

Cieri M and McCauley R (2007) Participatory theatre: creating a source for staging an example in the USA. In Kindon, S., Pain, R. and Kesby, M., editors, Connecting people, participation and place: participatory action research approaches and methods, London: Routledge

Cope, M. (2009) Challenging adult perspectives on children's geographies through participatory research methods: insights from a service-learning course. Journal of Geography in Higher Education 33, 1,

Elwood, S. (2007) Making space for integrative research and teaching. Environment and Planning A 39, 2291-96

Elwood, S. (2009) Integrating participatory action research and GIS education: negotiating methodologies, politics and technologies. Journal of Geography in Higher Education 33, 1, 51-65

Fine, M., Tuck, J.E. and Zeller-Berkman, S. (2007) Do you believe in Geneva? In N. Denzin, L.T. Smith and Y. Lincoln, Handbook of Critical and Indigenous Knowledges. Beverley Hills: Sage Publications.

Freire, P. (1972) Pedagogy of the Oppressed. (Harmondsworth: Penguin) 
Gibson-Graham, J. K. (2006) A postcapitalist politics University of Minnesota Press, Minneapolis

Healey, M. (2005) Linking research and teaching to benefit student learning, Journal of Geography in Higher Education, 29(2), pp. 183-201.

Hofman N and Rosing H (Eds) (2007) Pedagogies of Practice: course-based action research in the social sciences. (Boston, MA: Anker Publishing)

Hopkins, P. E. (2006) Youth transitions and going to university: the perceptions of students attending a geography summer school access programme, Area 2006, 38(3), pp. 240-247.

Howitt R (2001) Constructing engagement: geographical education for justice within and beyond tertiary classrooms. Journal of Geography in Higher Education 25, 2, 147-66

Hume-Cook, G. T. Curtis, J. Potaka, A. Tangaroa Wagner, K. Woods and S. Kindon (2007) Uniting People with Place through Participatory Video: A Ngaati Hauiti Journey. In Kindon, S. R. Pain and M. Kesby (eds) Participatory Action Research: Connecting People, Participation and Place, Routledge, London: 160-69.

Kesby, M. (2000) Participatory diagramming: deploying qualitative methods through an action research epistemology, Area, 32(4), pp. 423-35.

Kesby, M., Kindon, S. and Pain, R. (2005) Participatory research, in: R. Flowerdew and D. Martin (Eds.) Methods in Human Geography, pp. 144-66, (London: Pearson).

Kindon, S., Pain, R. and Kesby, M. (2007) Participatory Action Research Approaches and Methods: Connecting People, Participation and Place (London, Routledge)

Kindon, S. and Elwood, S. (2009) Introduction: more than methods - reflections on participatory action research in geographic teaching, learning and research. Journal of Geography in Higher Education 33, 1, 19-32

Le Heron, R., Baker, R. and McEwan, L. (2006) Co-learning: re-linking research and teaching in geography, Journal of Geography in Higher Education, 30(1), pp. 77-87.

Maddison, E. and Laing, S. (2007) The CUPP model in context' in A. Hart, E. Maddison, and D. Wolff (eds) Community-University Partnerships in Practice. Leicester: National Institute of Adult Continuing Education.

McNicoll, P. (1999) Issues in teaching participatory action research. Journal of Social Work Education 35, 1, 51-62

Moss, P. (2009) Positioning a feminist supervisor in graduate supervision. Journal of Geography in Higher Education 33, 1, 67-80 
Motta, S. (forthcoming) Teaching global and social justice as transgressive spaces of possibility. Antipode

Mountz, A., Moore, E. B. and Brown, L. (forthcoming, 2008) Participatory Action Research as pedagogy: boundaries in Syracuse, ACME: An International E-Journal for Critical Geographies

mrs kinpaisby (2008) Taking stock of participatory geographies: envisioning the communiversity. Transactions of the Institute of British Geographers 33, 3, 292-99

Pain R (2003) Social geography: on action-orientated research. Progress in Human Geography 27, 5, 677-85

Pain R (2009) Working across distant spaces: connecting Participatory Action Research and Teaching. Journal of Geography in Higher Education 33, 1, 81-87

Pain, R. and Kindon, S. (2007) Participatory geographies. Environment and Planning A 39, pp. 2807-12.

Pratt, G. (2007) Working with migrant communities: collaborating with the Kalayaan Centre in Vancouver, Canada, in: Kindon, S., Pain, R. and Kesby, M. (Eds.) Participatory Action Research Approaches and Methods: Connecting People, Participation and Place. (London: Routledge).

Russell, A., A. Cattermole, R. Hudson, S. Banks, A. Armstrong, F. Robinson, R. Pain, S. Gollan, G. Brown (2011) Sustaining Community-University Collaborations: the Durham University Model. Gateways: International Journal of Community Research and Engagement, 4, 218231

Savin-Baden, M. and Wimpenny, K. (2007) Exploring and implementing participatory action research. Journal of Geography in Higher Education 31, 2, 331-43 